\title{
THE LAUGHLEN TEST
}

\section{WITH PARTICULAR REFERENCE TO ITS SUITABILITY AS A PRELIMINARY SCREEN TEST}

\author{
BY \\ B. R. SANDIFORD \\ and \\ Formerly Director, Bacteriological Section \\ ANTOINETTE M. KHAL \\ Bacteriologist \\ From The Laboratories Department, Ministry of Public Health, Cairo
}

Since Laughlen's original papers $(1935,1938)$ describing his slide flocculation test for syphilis, several favourable reports on the method have been published and various modifications, mostly in the mode of preparation of the antigen, have been suggested. Such a simple test would be of obvious value where very large numbers of sera have to be dealt with, either as a parallel test or as a preliminary screen test.

This paper records an investigation into its suitability for such purpose. The following abbreviations are employed: W.R. for Wassermann Reaction ; K.T. for Kahn Test ; L.T. for Laughlen Test.

\section{Technique}

Preparation of Antigen.-For bulk preparation we have found $50 \mathrm{ml}$. Nessler tubes ideal : their width in relation to length permits of rapid pouring, and their flat bottom facilitates estimation of the amount of precipitate formed.

Take three of these-scrupulously clean, as must be all glassware used : fill one up to the $50 \mathrm{ml}$. mark with freshly prepared 1.5 per cent. saline, close with cork covered with "silver" foil or cellophane-as must be all corks used-and immerse it in a water-bath at $50^{\circ} \mathrm{C}$. Into another tube place $5 \mathrm{ml}$. of Kahn antigen and $20 \mathrm{mg}$. of Scarlet R stain (we are using Gurr's). With a glass rod briefly triturate the stain in the antigen, cork the tube, and place it in the $50^{\circ} \mathrm{C}$. water-bath for four minutes, by which time the contents of both tubes should have attained the bath temperature. Take out the antigen-stain mixture, give it a fêw shakes and quickly drop into it, shaking gently the while, eleven drops of Tinct. Benzoin. Co. from a Dreyer standard dropping pipette (twenty-two drops from a No 56 Standard Wire Gauge dropping pipette). Without loss of time remove the tube of saline from the bath, wipe it dry, and empty it into the antigen-stain. Rapidly pour the mixture back and forth four or five times without pausing to drain the tubes completely. Cork the tube and place in the $50^{\circ} \mathrm{C}$. water-bath for two minutes, after which allow it to stand on the bench for twenty minutes. The particles of undissolved stain will, by now, have settled to the bottom of the tube and the supernatant fluid can be decanted into the third Nessler tube, which is set aside at room temperature for twenty-four hours. When room temperatures have been high we have used a $22^{\circ} \mathrm{C}$. incubator for storage.

The antigen is now ready for testing with known negative, weakly positive, and strongly positive sera (see below for method). Usually, in our experience, it has not been sensitive enough at this stage, reacting -if at all-with only strongly positive sera. Sensitization is effected by adding strong saline (10 per cent.) or saturated ammonium sulphate solution. We have used the latter, though, if one is making up small amounts of antigen, saline is better, as only a few drops of ammonium sulphate are necessary even for $50 \mathrm{ml}$. amount of antigen ; 10 per cent. saline, we find, has about one-eighth the sensitizing power of ammonium sulphate. The antigen is now again set aside overnight before retesting and, if necessary, readjusting. This process is repeated as many times as is necessary. In practice, trouble and time may be saved, when one has learnt the requirements of antigens made up from a particular Kahn antigen, by adding rather less than the estimated amount of sensitizing electrolyte to the Laughlen antigen as soon as its preparation has been completed, and then correcting again after twenty-four hours if necessary. A useful rough guide to the sensitivity of an antigen is the amount of precipitation which takes place on standing. In keeping records for future guidance a "four plus" notation may be employed, thus :

$$
\begin{aligned}
& \text { "pp. } 0 "=\text { no precipitation. } \\
& \text { pp. } 1 "=\begin{array}{c}
\text { a little precipitation without apparent } \\
\text { clearing. }
\end{array} \\
& \text { "pp. } 2 "=\begin{array}{c}
\text { moderate precipitation with some } \\
\text { clearing. }
\end{array} \\
& \text { "pp. } 3 "=\begin{array}{c}
\text { heavy precipitation without complete } \\
\text { clearing. }
\end{array}
\end{aligned}
$$


"pp. $4 "=$ complete precipitation with water-clear supernatant fluid

The degree of sensitivity of an antigen, as determined against known Wassermann- and/or, Kahntested sera may similarly be recorded :

"ss. $0 "=$ not reacting with any sera.

"ss. 1" = reacting only with " ++++ " sera.

"ss. 2 " = reacting with " $+++"$ and stronger sera.

"ss. 3 " = reacting with " $++"$ and stronger sera.

"ss. 4 " = reacting with " + " sera.

"ss. $X "$ " reacting with some negative sera.

"ss.XX" = reacting with most negative sera.

The following points concerning antigen sensitivity were noted.

1. The ratio ss/pp varies much more between antigens made from different Kahn antigens than it does between those made from the same antigen. Whilst, for instance, one made from a certain Kahn antigen may be "ss.4" at "pp.1," that made from another may be only " ss.1" at " pp.1" and require addition of electrolyte to " pp. 3 " to bring it up to "ss.4."

2. Laughlen antigen becomes progressively more sensitive the longer it is kept, and this increase is the more rapid for a certain period the more sensitive the antigen was at the beginning of that period. Thus- whilst one of " ss.0" may be kept for several weeks without much change, one of "ss.4" may only be used for about seven to ten days, after which it will become progressively "ss.X" and "ss.XX."

3. An antigen at " pp. 4 " will usually be " ss.X" or "ss.XX"; the converse, however, is not necessarily true.

Performance of the Test.-The principle of the test is to mix drops of antigen and sera and to observe the formation of floccules.

Apparatus. $\rightarrow$ In our initial experiments we tried both hollowed porcelain tiles and hollowed glass slides such as are sometimes used for blood-grouping. Both these we discarded in favour of big glass slides as used in the Garrod slide agglutinometer. Eventually we found the ideal article in rectangular museum-jar lids $30 \mathrm{~cm}$. long by $4.5 \mathrm{~cm}$. wide with a frosted or ground strip $0.75 \mathrm{~cm}$. wide round the edges. This frosted band serves the useful purpose of preventing mingling of drops at the edge of the slide to which their access is prevented, but it is not essential. The inner rectangle of clear glass is marked off into twenty strips $1.0 \mathrm{~cm}$. wide by deep double rulings which may be made with a diamond.

Method.-The sera to be tested must first be inactivated in a water-bath at $56^{\circ} \mathrm{C}$. for twenty minutes, otherwise we find false positives or negatives will result in a number of cases. Using Dreyer standard dropping
TABLE I

SERIES I-SHOWING REACTIONS OF 500 SERA

\begin{tabular}{|c|c|c|c|c|}
\hline & \multicolumn{2}{|c|}{ W.R. negative } & \multicolumn{2}{|c|}{ W.R. positive } \\
\hline \multirow{3}{*}{$\begin{array}{l}\text { Laughlen } \\
\text { negative }\end{array}$} & \multirow{3}{*}{\multicolumn{2}{|c|}{$\begin{array}{c}374 \\
(74.8 \%)\end{array}$}} & \multicolumn{2}{|c|}{$2(0.4 \%)$} \\
\hline & & & K.T. pos. & K.T. neg. \\
\hline & & & $\begin{array}{c}0 \\
(0.0 \%)\end{array}$ & $\begin{array}{c}2 \\
(0.4 \%)\end{array}$ \\
\hline \multirow{3}{*}{$\begin{array}{l}\text { Laughlen } \\
\text { positive }\end{array}$} & \multicolumn{2}{|c|}{$15(3 \%)$} & \multirow{3}{*}{\multicolumn{2}{|c|}{$\begin{array}{c}109 \\
(21 \cdot 8 \%)\end{array}$}} \\
\hline & K.T. pos. & K.T. neg. & & \\
\hline & $\begin{array}{c}2 \\
(0 \cdot 4 \%)\end{array}$ & $\begin{array}{c}13 \\
(2 \cdot 6 \%)\end{array}$ & & \\
\hline
\end{tabular}

N.B. In all tables except $V$, percentages are approximated to the first decimal place.

pipettes, one drop of each serum is dropped into each space and then a drop of antigen. The slide is then rocked slowly to and fro for ten minutes and the results read.

Prevention of drying.-Drying presents a problem in warm weather, even a slight degree produces a false granularity at the edges of the specimens. We have overcome this by the use of cylindrical museum-jars (internally, $32 \mathrm{~cm} . \times 5.3 \mathrm{~cm}$.). A strip of moist cotton wool is laid inside, the slide inserted, and the lid stuck on with a trace of vaseline. The jar may then conveniently be laid on the bench and rolled to and fro. Clouding of the jar's internal surface, if troublesome, may be prevented by occasional swabbing with bile. It is not advisable to have the wool too wet lest moisture condense on the slide.

Reading and recording of results.-Reading is most easily and accurately done by holding the slide over a narrow light source in a black background, the specimens being examined obliquely against the latter. We used a flat-topped microscope lamp with a central hole. $A$ lens is unnecessary and undesirable.

Our results were recorded on a " $4+$ " notation according to the degree of flocculation produced. The value of this quantitative method of reading is discussed below.

\section{Experimental Results}

Our results are given in three series recorded respectively in Tables I, II, and III.

Series I. - This was a comparatively small series done by one person in small batches at a time. It served to confirm uxperience as to the reliability of the test gained with over a thousand specimens in preliminary trials. For this series, only specimens with plenty of serum were selected; where there was disagreement between the Wassermann reaction and the Laughlen test, a Kahn test was done. 
TABLE II

SERIES II-SHOWING REACTIONS OF 2,500 SERA

\begin{tabular}{|c|c|c|c|c|}
\hline \multirow{4}{*}{$\begin{array}{l}\text { Laughlen } \\
\text { negative }\end{array}$} & \multicolumn{2}{|c|}{ W.R. negative } & \multicolumn{2}{|c|}{ W.R. positive } \\
\hline & \multirow{3}{*}{\multicolumn{2}{|c|}{$\begin{array}{c}1,960 \\
(78 \cdot 4 \%)\end{array}$}} & \multicolumn{2}{|c|}{$54(2 \cdot 2 \%)$} \\
\hline & & & K.T. pos. & K.T. neg. \\
\hline & & & $\begin{array}{c}5^{*} \\
(0 \cdot 2 \%)\end{array}$ & $\begin{array}{c}49^{*} \\
(2 \cdot 0 \%)\end{array}$ \\
\hline \multirow{3}{*}{$\begin{array}{l}\text { Laughlen } \\
\text { positive }\end{array}$} & \multicolumn{2}{|c|}{$113(4 \cdot 5 \%)$} & \multirow{3}{*}{\multicolumn{2}{|c|}{$\begin{array}{c}373 \\
(14.9 \%)\end{array}$}} \\
\hline & K.T. pos. & K.T. neg. & & \\
\hline & $\begin{array}{c}18^{*} \\
(0 \cdot 7 \%)\end{array}$ & $\begin{array}{c}95^{*} \\
(3 \cdot 8 \%)\end{array}$ & & \\
\hline
\end{tabular}

* Computed : 83 of the 113 (L.T.+W.R. -) sera were done K.T. and 46 of the 54 (L.T. - W.R.+).

Series II.-This was undertaken on the same lines as series I. Laughlen and Wassermann tests were done on every specimen, and a Kahn test where there was disagreement if serum was available. It was carried out in large daily batches by a routine team consisting of one bacterioTogist, one laboratory assistant, and two laboratory boys.

The routine used was as follows :

The bacteriologist drops the sera and antigen on to a slide and boy " $A$ " takes it and commences rocking; a laboratory alarm clock is set to ring every five minutes. Meanwhile, another slide is filled by the end of the first five minutes (the operation actually only takes two or three minutes) and handed to boy "B." A third slide is filled by the end of the second five minutes when it is handed to boy " $A$ " from whom the first slide is taken

TABLE III

SERIES II-SHOWING REACTIONS OF 20,000 SERA

\begin{tabular}{|c|c|c|c|c|}
\hline \multirow{4}{*}{$\begin{array}{l}\text { Laughlen } \\
\text { negative }\end{array}$} & \multicolumn{2}{|c|}{ W.R. negative } & \multicolumn{2}{|c|}{ W.R. positive } \\
\hline & \multirow{3}{*}{\multicolumn{2}{|c|}{$\begin{array}{c}14,846 \\
(74 \cdot 2 \%)\end{array}$}} & \multicolumn{2}{|c|}{$254(1 \cdot 3 \%)$} \\
\hline & & & K.T. pos. & K.T. neg. \\
\hline & & & $\begin{array}{c}45^{*} \\
(0 \cdot 2 \%)\end{array}$ & $\begin{array}{c}209^{*} \\
(1 \cdot 1 \%)\end{array}$ \\
\hline \multirow{3}{*}{$\begin{array}{l}\text { Laughlen } \\
\text { positive }\end{array}$} & \multicolumn{2}{|c|}{$\begin{array}{c}1,230 \\
.(6 \cdot 2 \%)\end{array}$} & \multirow{3}{*}{\multicolumn{2}{|c|}{$\begin{array}{c}3,670 \\
(18 \cdot 4 \%)\end{array}$}} \\
\hline & K.T. pos. & K.T. neg. & & \\
\hline & $\begin{array}{c}793 * \\
(4 \cdot 0 \%)\end{array}$ & $\begin{array}{c}437 * \\
2 \cdot 2 \%)\end{array}$ & & \\
\hline
\end{tabular}

* Computed: 729 of the 1,230 (L.T.+W.R. -) sera were done K.T. and 153 of the 254 (L.T. -W.R.t). for reading. This must be completed and another slide filled within five minutes for boy " $B$ " to take in place of the second slide which is now ready for readingand so on. The assistant rinses pipettes and slides and writes down the results called by the bacteriologist. By this arrangement 200 or more specimens may be done in an hour, even allowing for an odd break or two in the routine sequence.

TABLE IV

SERIES I, II, AND III-SHOWING REACTIONS OF 23,000 SERA

\begin{tabular}{|c|c|c|c|c|}
\hline \multirow{4}{*}{$\begin{array}{l}\text { Laughlen } \\
\text { negative }\end{array}$} & \multicolumn{2}{|c|}{ W.R. negative } & \multicolumn{2}{|c|}{ W.R. positive } \\
\hline & \multirow{3}{*}{\multicolumn{2}{|c|}{$\begin{array}{r}17,180 \\
(74 \cdot 2 \%)\end{array}$}} & \multicolumn{2}{|c|}{$310(1 \cdot 3 \%)$} \\
\hline & & & K.T. pos. & K.T. neg \\
\hline & & & $\begin{array}{c}50 \\
(0 \cdot 2 \%)\end{array}$ & $\begin{array}{c}260 \\
(1 \cdot 1 \%)\end{array}$ \\
\hline \multirow{3}{*}{$\begin{array}{c}\text { Laughlen } \\
\text { positive }\end{array}$} & \multicolumn{2}{|c|}{$\begin{array}{c}1,358 \\
(5.9 \%)\end{array}$} & \multirow{3}{*}{\multicolumn{2}{|c|}{$\begin{array}{c}4,152 \\
(18 \cdot 1 \%)\end{array}$}} \\
\hline & K.T. pos. & K.T.neg. & & \\
\hline & $\begin{array}{c}813 \\
(3 \cdot 5 \%)\end{array}$ & $\begin{array}{c}545 \\
(2 \cdot 4 \%)\end{array}$ & & \\
\hline
\end{tabular}

Series III.-This was also carried out by the routine team, but, as an added check on technical errors, where specimens showed disagreement between L.T. and W.R., the L.T. and W.R. were repeated and, if there was still disagreement, the K.T. was then done. When there was insufficient serum to repeat the W.R., the original W.R. result was accepted, but the L.T. was repeated and this second L.T. result (which very seldom differed from its original) accepted.

\section{Discussion of Results}

Since the object of this investigation was to determine the reliability of the Laughlen reaction as an exclusion screen test, we shall confine discussion to that aspect of our results.

From Table IV, which summarizes the results of all three series, it will be seen that, of the 23,000 sera examined, 92.5 per cent. (approximately) agreed in their Laughlen and Wassermann reactions and 7.5 per cent. disagreed.

But we are chiefly interested in the percentage which gave a false Laughlen-negative (L.T.-W.R. +K.T +.), which is only 0.2 per cent. of the total sera examined and 1.1 per cent. of the sera positive by both W.R. and K.T. These results compare well with those of other workers (Table V).

Admittedly, the L.T. misses a higher percentage of positives if its results are compared only with the W.R. results, 1.3 per cent. of the total sera examined 
TABLE V

SHOWING PERCENTAGES OF "FALSE L.T. NEGATIVES" (L.T. - W.R. + K.T. +)

\begin{tabular}{|c|c|c|}
\hline - & $\begin{array}{c}\text { Of total sera } \\
\text { examined }\end{array}$ & $\begin{array}{c}\text { Of positive } \\
\text { sera (W.R. }+ \\
\text { K.T. }+ \text { ) }\end{array}$ \\
\hline Our Series I & 0.00 & 0.00 \\
\hline Our Series I, II, and III .. & 0.20 & $1 \cdot 10$ \\
\hline $\begin{array}{c}\text { Hamiltorr-Paterson, Cole, } \\
\text { and Usher (1944) }\end{array}$ & 0.02 & 0.59 \\
\hline Lane (1944) & 0.05 & $0 \cdot 50$ \\
\hline
\end{tabular}

and 6.9 per cent. of the positive (W.R.) sera. Against these, however, we must offset the positives which the L.T. picked up and the W.R. missed (L.T. +W.R.-K.T. +), which amount to 3.5 per cent. of the total sera ; so that, on balance, the L.T. used as a preliminary screen test would pick out more positives than the W.R. used alone.

It is well known that in any series of luetic sera there will be some which react only with the W.R. or K.T. but rot with both, and that it is better routine practice to do a complement fixation and a flocculation test on all sera. Where pressure of, work precludes this, the L.T. test in conjunction with the W.R. offers a useful alternative.

\section{The Quantitative Laughlen Test}

The degree of flocculation has generally been regarded as indicative of the degree of positivity of a serum, but Price (1939) found the speed of the flocculation to be a surer guide.

It was impossible for us to do more than record the amount of flocculation, ranging from complete $(++++)$ to a fine granulation just detectable to the naked eye $( \pm)$, included with the positives in our records.

The results of the 373 L.T.+W.R.+sera of Series II recorded in Table VI were submitted to Prof. F. E. Relton of the Mathematics Department, Fouad First University, for statistical treatment.

$\mathrm{He}$ found that there is an even chance that the
TABLE VII

SHOWING REACTIONS OF ONE HUNDRED CEREBROSPINAL FLUIDS

\begin{tabular}{|c|c|c|c|c|}
\hline \multirow{4}{*}{$\begin{array}{l}\text { Laughlen } \\
\text { negative }\end{array}$} & \multicolumn{2}{|c|}{ W.R. negative } & \multicolumn{2}{|c|}{ W.R. positive } \\
\hline & \multirow{3}{*}{\multicolumn{2}{|c|}{70}} & \multicolumn{2}{|c|}{6} \\
\hline & & & K.T. pos. & $\begin{array}{c}\text { K.T. neg. } \\
2\end{array}$ \\
\hline & & & \multicolumn{2}{|c|}{ No C.S.F. in 4 cases } \\
\hline \multirow{3}{*}{$\begin{array}{l}\text { Laughlen } \\
\text { positive }\end{array}$} & \multicolumn{2}{|c|}{2} & \multirow{3}{*}{\multicolumn{2}{|c|}{22}} \\
\hline & K.T. pos. & K.T. neg. & & \\
\hline & 0 & 2 & & \\
\hline
\end{tabular}

Laughlen reading, based on amount of flocculation, will be within one degree of that given by the "four plus "Wassermann. It is obvious from the table that very weakly or very strongly reacting sera show much better quantitative agreement between the two tests.

\section{Cerebrospinal Fluids}

The L.T. has been variously reported on as regards its applicability for the testing of C.S.Fs. In our experience it has shown itself valuable for this purpose (Table VII).

\section{Conclusions}

1. The Laughlen test is reliable as a screen or parallel test.

2. Sera must be heat-inactivated before testing.

3. It is suitable for the examination of cerebrospinal fluids.

4. The degree of flocculation produced is not of much value as a quantitative result, unless it be maximal or minimal.

\section{REFERENCES}

Hamilton-Paterson, J. L., Cole, W. T. S., and Usher, G. L. C. (1944). J. Path. Bact., 56, 335.

Lane, C. R. (1944). Brit. J. vener. Dis., $20,78$.

Laughlen, G. F. (1935). Canad. med. Ass. J., 33, 179. (1938). Canad. Publ. Hlth J., 29, 396.

Price, A. S. (1939). N.Y. State J. Med., 39, 880.

TABLE VI

SERIES II - SHOWING QUANTITATIVE READINGS OF 373 POSITIVE SERA

\begin{tabular}{|c|c|c|c|c|c|c|c|c|c|c|c|c|c|c|c|c|c|c|c|c|c|c|c|c|c|}
\hline L.T. & \multicolumn{5}{|c|}{ \pm 73} & \multicolumn{5}{|c|}{+55} & \multicolumn{5}{|c|}{++29} & \multicolumn{5}{|c|}{+++24} & \multicolumn{5}{|c|}{++++192} \\
\hline W.R. & \pm & +1 & +2 & +3 & +4 & \pm & +1 & +2 & +3 & +4 & \pm & +1 & +2 & +3 & +4 & \pm & & +2 & +3 & +4 & \pm & +1 & +2 & +3 & +4 \\
\hline & 40 & 10 & 9 & 3 & 11 & 14 & 6 & 15 & 3 & 17 & 13 & 3 & 7 & 1 & 5 & 1 & 0 & 9 & 6 & 8 & 5 & 1 & 12 & 20 & 154 \\
\hline
\end{tabular}

